Available online at www.iponlinejournal.com

\title{
Replantation of avulsed incisor: A Case report
}

\author{
Ashvini K Vadane ${ }^{1 *} J B$ Garde $^{2}$ \\ ${ }^{1}$ Senior Lecturer, ${ }^{2}$ Professor and HOD, ${ }^{1,2}$ Dept. of Oral and Maxillofacial Surgery, ${ }^{1,2} \mathrm{M}$ A Rangoonwala College of Dental Science and \\ Research Centre, Pune, Maharashtra, India
}

\begin{abstract}
The complete displacement of tooth from its alveolar socket is known as "tooth avulsion". This case report describes the management of avulsed central incisor tooth in 8 year old male patient. This tooth was replanted in the socket and was further treated endodontic treatment and antibiotics. This case was successfully managed.
\end{abstract}

Keywords: Avulsion, Replantation, Trauma, Tooth avulsion.

\section{Introduction}

Tooth avulsion, tooth fracture, soft tissue laceration and tooth laceration are various traumatic dental injuries which occur in paediatric age group. ${ }^{2}$ The complete displacement of tooth from its alveolar socket is known as "tooth avulsion". 1

Tooth avulsion is classified as periodontal tissue injury by WHO (World Health Organization) Classification System. $^{2}$ Almost $0.5 \%$ to $3 \%$ of dental injuries are accounted by tooth avulsion. During the ages of 7 years to 9 years, the prevalence of tooth avulsion increases as there is incomplete development of root as well as less resistance of alveolar bone. In case of deciduous dentition, tooth avulsion occurs mainly because of hit by hard objects and in permanent teeth, avulsion is a result of trauma or accidents. Tooth avulsion is most commonly seen in maxillary teeth and central incisors are most commonly affected. ${ }^{1}$ This article describes the successful management of avulsed central incisor in 8 year old child by replantation and endodontic treatment.

\section{Case Report}

A 8 years old male patient visited our institute with the chief complaint of avulsion of maxillary left central incisor due to fall. Patient had trauma 1 day prior when he had fallen down. Paient's parents had collected that avulsed tooth and had stored it in milk and next day visited our institute. On clinical examination, there were no any lacerations or soft tissue injuries. We decided to perform the replantation of tooth under local anaesthesia. We explained the whole surgical procedure and treatment to the patient and to his parents. All consents were obtained. Patient's tooth was replanted at its anatomical position and was fixed with splinting and wiring. Antibiotics were administered to the patient. Proper follow up was maintained. Patient and his parents were been explained about the necessity of endodontic treatment, i.e., root canal treatment of that tooth (maxillary left central incisor tooth) in future. In this way, the case was successfully managed.

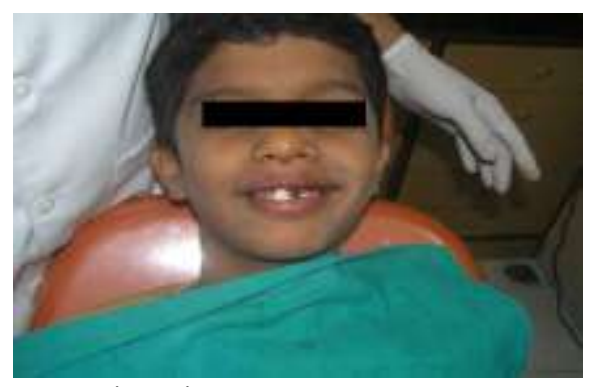

Fig. 1: Preoperative Picture

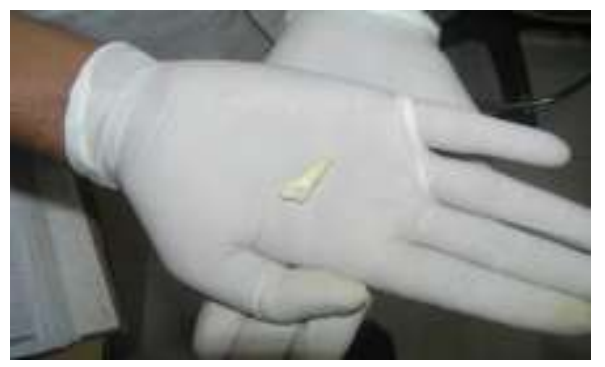

Fig. 2: Avulsed Tooth

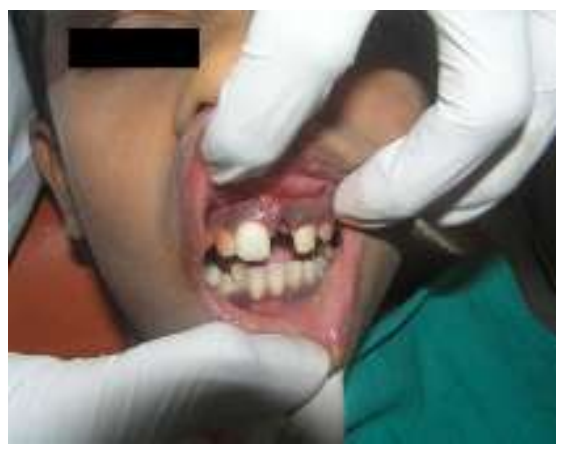

Fig. 3: Clinical picture of avulsed tooth socket

\footnotetext{
*Corresponding Author: Ashvini K Vadane, Senior Lecturer, Dept. of Oral and Maxillofacial Surgery, M A Rangoonwala College of Dental Science and Research Centre, Pune, Maharashtra, India

Email: drashvinivadane@gmail.com

http://doi.org/10.18231/j.idjsr.2019.020
} 


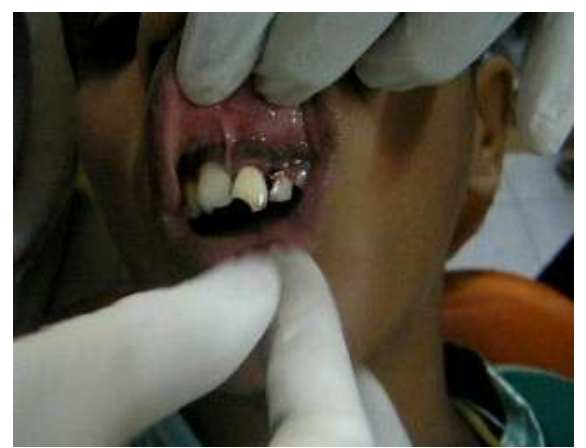

Fig. 4: Placement of avulsed tooth at its anatomical position

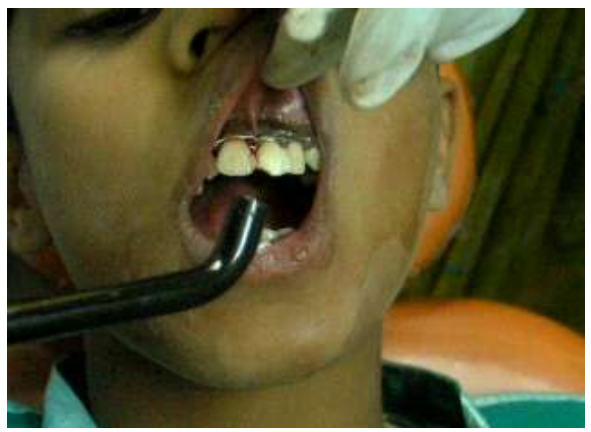

Fig. 5: Splinting of avulsed tooth

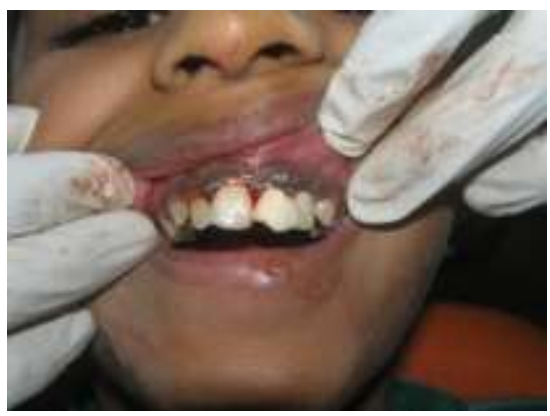

Fig. 6: Immediate postoperative picture

\section{Discussion}

The complete displacement of tooth from its normal anatomical position, i.e., alveolar socket is known as "tooth avulsion". Avulsion injuries are thrice more common in males as compared to females. ${ }^{2}$ Immediate replantation is the ideal treatment for avulsed teeth. The condition of the periodontal ligament cells and root apex maturity are the factors taken to be in the consideration while deciding treatment plan of avulsed teeth. Storage medium and time period elapsed after the avulsion of tooth affects on the condition of periodontal ligament cells. According to clinical studies, if avulsed teeth are replanted within 5 minutes, prognosis and success rate is good. After an hour after tooth avulsion, all periodontal ligament cells become nonviable. Patient's own saliva, saline, milk and "Hank's Balanced Salt Solution"(HBSS) are suitable media for storage of tooth after avulsion. ${ }^{1}$ Various storage media like endogain, egg white, tap water, contact lens solution can also be used for storage of avulsed tooth. ${ }^{2}$ Replantation of avulsed primary teeth is the topic of debate in dental literature. $^{3}$

\section{Conclusion}

Tooth avulsion can be considered as dental emergency and it should be treated as soon as possible. Time period elapsed after the tooth avulsion affects the prognosis of tooth after the replantation. Tooth avulsion at an early age can deteriotes patient's appearance and can hamper patient's psychology. ${ }^{3}$ Hence, it is important that every dental practitioner should have recent and well knowledge about the management of avulsed teeth. ${ }^{2}$

\section{Source of Funding \\ None.}

\section{Conflict of Interest}

None.

\section{References}

1. Savas S. Delayed Replantation of Avulsed Teeth: Two Case Reports. Case Rep Dent 2015, Article ID 197202

2. Pradhan D. Tooth avulsion - A Dental emergency in children: A Review. Am J Adv Med Sci 2014;2(3):15-20

3. Acharya S. Avulsion and replantation of primary teeth $-\mathrm{A}$ feasible option. Dent Case Rep 2017;1

4. Martin Trope. Avulsion of permanent teeth: Theory to practice. Dent Traumatol 2011.

5. Kubasad G. Replantation of an avulsed tooth with an extended extra oral period. Indian J Dent Res 23 (6), 2012

6. Krishnapriya Suhas Nene and Vikas Bendgude. Prognosis of Replanted Avulsed Permanent Incisors: A Systematic Review. Int J Pedod Rehabil 2018;3:87-98

7. Kolli NKR. Delayed replantation of avulsed tooth with $4 \frac{1}{2}$ days extraoral time with 18 months follow up. J NTR Univ Health Sci 2017;6:136-9.

8. Tezel H. Replantation after traumatic avulsion. Eur J Dent 2013;7(2):229-32.

9. Joseph C. Kehoe. Spliniting and replantation after traumatic avulsion. JADA 112(2):224-30.

10. Anupam Saha et al. Delayed replantation of avulsed permanent maxillary central incisor - with unfavorable outcome after 12 months. SRM J Res Dent Sci 2017;8:171-4.

11. Kostka E. Multidisciplinary Treatment Options of Tooth Avulsion Considering Different Therapy. Open Dent $J$ 2014;8:180-183

12. Koca H. Delayed replantation of an avulsed tooth after 5 hours of storage in saliva; case report. Dent Traumatol 2010;26:3703 .

13. Andersson. International association of dental traumatology guidelines for the management of traumatic dental injuries: 2 . Avulsion of permanent teeth. Dent Traumatol 2012;28:88-96.

14. Day P and Duggal M. Interventions for treating traumatized permanent front teeth: avulsed (knocked out) and replanted. Conchrane Database Syst Rev 2010;(1):CD006542.

15. Petrovic B. Factors related to treatment and outcomes of avulsed teeth. Dent Traumatol 2010;26:52-9.

How to cite this article: Vadane AK. Replantation of avulsed incisor: A Case report, Int Dent J Student Res 2019;7(3):79-80 